\title{
Treatment of steroid-dependent bronchial asthma with cyclosporin
}

\author{
E. Niżankowska, J. Soja, G. Pinis, G. Bochenek, K. Sładek, \\ B. Domagała, A. Pajak, A. Szczeklik
}

Treatment of steroid-dependent bronchial asthma with cyclosporin. E. Niżankowska, J. Soja, G. Pinis, G. Bochenek, K. Sładek, B. Domagała, A. Pajak, A. Szczeklik. @ CERS Journals Ltd 1995.

ABSTRACT: The treatment of chronic severe asthma is unsatisfactory for many patients. The aim of the study was to determine the effects of treatment of steroiddependent asthma with cyclosporin.

We performed a double-blind, placebo-controlled, randomized, parallel group trial on the effect of cyclosporin on pulmonary function, asthma severity and tapering of prednisone in $\mathbf{3 4}$ steroid-dependent asthmatics (mean oral prednisone dose: 16 mg•day $\left.^{-1}\right)$. The study consisted of: 1) baseline period (12 weeks); 2) experimental period divided into two parts: Part I (12 weeks) cyclosporin or placebo treatment; Part II (22 weeks) cyclosporin or placebo treatment and oral prednisone reduction; and 3 ) follow-up observation (8 weeks). Asthma symptoms score, pulmonary function tests (daily peak expiratory flow (PEF) and bi-weekly forced vital capacity (FVC), forced expiratory volume in one second (FEV1) and maximal midexpiratory flow (MEF50), biochemical profile and blood cyclosporin levels were monitored throughout the study.

Following cyclosporin administration, a slight beneficial effect on some subjective parameters of asthma severity was observed. At the same time, no beneficial effect on pulmonary function was noted. The time trends analysis of mean daily prednisone doses between the treatment groups revealed a statistically significant difference indicating that, during prednisone reduction, cyclosporin seemed to be slightly more efficient than placebo in reducing the requirement for systemic corticosteroid, even though the steroid reduction was accompanied by slight impairment of some pulmonary function. However, there was no significant difference in the final dose reduction between the treatment groups.

These data and the known toxicity of the drug suggest a limited place for cyclosporin treatment in steroid-dependent bronchial asthma.

Eur Respir J., 1995, 8, 1091-1099.
Dept of Medicine, Jagiellonian University School of Medicine, Cracow, Poland.

Correspondence: A. Szczeklik

Dept of Medicine

Jagiellonian University School of Medicine Skawińska 8

31-066 Cracow

Poland

Keywords: Asthma

cyclosporin

steroid-dependent asthma

steroid-sparing effect

Received: August 311994

Accepted after revision March 251995

Supported by The Polish-American Marie Skrodowska-Curie grant No. MZ/HHS-9177, and the Polish State Research Council grant No. 501/G/53.
Airway inflammation seems to be a common mechanism underlying asthma, and therapeutic efforts have focused on reduction of this inflammation [1]. The drugs with topical anti-inflammatory activity, such as inhaled corticosteroids, disodium cromoglycate and nedocromil sodium, improve asthma symptoms and reduce bronchial hyperresponsiveness. Systemic corticosteroids are sometimes required to control asthma; however, some severe asthmatics are refractory to their therapeutic action [2]. Chronic systemic administration of corticosteroid is usually associated with serious and sometimes irreversible side-effects. The physician is challenged to develop a treatment regimen that will control the incapacitating and potentially life-threatening consequences of severe asthma without devastating iatrogenic side-effects. Several investigators have sought a "steroid-sparing" agent, that would allow corticosteroid doses to be reduced whilst maintaining adequate and stable pulmonary function. The agents tried include: gold salts [3], methotrexate [4,
5], troleandomycin [6], nedocromil sodium [7], azathioprine [8], dapsone [9], and high-dose beclomethasone [10].

Recent evidence suggests that T-lymphocytes may participate in the pathogenesis of allergic inflammation and asthma [11], perhaps by releasing cytokines involved in the recruitment, activation and differentiation of inflammatory cells, e.g. mastocytes and eosinophils. In blood, the number of activated CD4+ (CD25) T-lymphocytes correlates with asthma severity [11]. Cyclosporin is thought to exert its immunosuppressive activity primarily by depressing T-lymphocyte activation via inhibition of transcription of several messenger ribonucleic acid (mRNA) lymphokines $[12,13]$. The drug inhibits the release of preformed and de novo synthesized mediators from human lung and skin mast cells and basophils [14, 15]. It also inhibits the expression of several cytokines in these cells [16]. All of these mediators and cytokines may profoundly influence immune responses and the intensity of inflammation in bronchial asthma. 
In several diseases thought to be mediated by activated T-lymphocytes and treated with corticosteroids, cyclosporin therapy was effective. These include: rheumatoid arthritis [17], psoriasis [18], and atopic dermatitis [19].

We have recently introduced cyclosporin for treatment of asthma, and in an open study we observed its steroidsparing effect in almost half of severe asthmatics [20, 22]. Others have confirmed this observation [23]. This effect, however, was not usually sustained and waned with cessation of the drug's administration [22]. In a subsequent double-blind trial, cyclosporin was shown to improve pulmonary function in corticosteroid-dependent chronic asthmatics [24]. The aim of this study was to determine in a double-blind, randomized, placebo-controlled, parallel group trial the effects of cyclosporin treatment on asthma symptoms, lung function and corticosteroid tapering in patients with severe, corticosteroid-dependent asthma.

\section{Patients and methods}

\section{Subjects}

Thirty four nonsmoking adults ( 27 females and 7 males, aged 25-57 yrs, average 42 yrs) with severe chronic asthma were recruited. All required long-term oral steroid treatment at a minimum dose of 5-35 mg daily, in addition to standard therapy consisting of theophylline, inhaled beclomethasone and $\beta$-mimetics. Patients had to respond with more than a $15 \%$ increase in forced expiratory volume in one second (FEV1) or in peak expiratory flow (PEF) following $200 \mu \mathrm{g}$ fenoterol inhalation (Boehringer Ingelheim, Germany). The lowest dose of prednisone on which each patient's asthma was relatively stable before entry, was used as the maintenance dose throughout the baseline period and during the first part of the experimental period. In all patients, at least one attempt to reduce corticosteroid dose was made during the 6 month period preceding the study. All such attempts were unsuccessful.

Excluded from the study were patients who had: other significant pulmonary diseases; impaired renal function (serum creatinine above $120 \mu \mathrm{mol} \cdot \mathrm{L}^{-1}$ or abnormal urinalysis); impaired liver function; systolic blood pressure $>160 \mathrm{mmHg}$ and/or diastolic blood pressure >95 $\mathrm{mmHg}$; acute or chronic infections; malignancy at any time; epilepsy; malabsorption; concomitant therapy with other immunosuppressants and drugs which interact adversely with cyclosporin. Women of child-bearing age who did not use effective contraception were also excluded.

Written, informed consent was obtained, and the study was approved by the Ethics Committee of the Jagiellonian University School of Medicine, Cracow. Patient characteristics are presented in table 1.

Thirteen of 34 patients had aspirin intolerance confirmed by oral challenge tests [25]; the remaining patients tolerated aspirin well. The relatively high percentage of aspirin-induced asthmatics can be attributed to the fact that we, as a research centre, have been concentrating
Table 1. - Clinical characteristics of cyclosporin (CS) and placebo $(P)$ groups at baseline

\begin{tabular}{|c|c|c|}
\hline $\begin{array}{l}\text { Characteristic } \\
\text { parameter }\end{array}$ & $\underset{n=17}{\text { CS group }}$ & $\mathrm{P}$ group \\
\hline Sex $F / M$ & $14 / 3$ & $13 / 4$ \\
\hline Age yrs* & $\begin{array}{c}42 \\
(27-55)\end{array}$ & $\begin{array}{c}43 \\
(27-58)\end{array}$ \\
\hline Duration of asthma yrs* & $\begin{array}{c}12 \\
(4-29)\end{array}$ & $\begin{array}{c}14 \\
(4-32)\end{array}$ \\
\hline $\begin{array}{l}\text { Duration of oral } \\
\text { corticosteroid therapy yrs* }\end{array}$ & $\begin{array}{c}8.5 \\
(2.5-22)\end{array}$ & $\begin{array}{c}7.7 \\
(3-17)\end{array}$ \\
\hline $\operatorname{IgE} \quad \mathrm{IU} \cdot \mathrm{mL}^{-1} *$ & $\begin{array}{c}124.2 \\
(36.4-432.4)\end{array}$ & $\begin{array}{c}159.1 \\
(17.9-879.0)\end{array}$ \\
\hline $\begin{array}{l}\text { Positive skin-prick } \\
\text { tests } \mathrm{n}\end{array}$ & 8 & 11 \\
\hline Aspirin intolerance & 7 & 6 \\
\hline Morning PEF L·min ${ }^{-1 \dagger}$ & $233(69)$ & $235(81)$ \\
\hline Evening PEF $\mathrm{L} \cdot \mathrm{min}^{-1 \dagger}$ & $261(71)$ & $269(76)$ \\
\hline $\mathrm{FVC} \mathrm{L}^{\dagger}$ & $2.9(1.0)$ & $2.6(0.9)$ \\
\hline FEV1 $L^{\dagger}$ & $2.1(0.8)$ & $1.9(0.8)$ \\
\hline $\mathrm{FEV}_{1 / \mathrm{FVC}} \%^{\dagger}$ & $74(12)$ & $75(13)$ \\
\hline MEF50 $\mathrm{L} \cdot \mathrm{s}^{-1 \dagger}$ & $2.3(1.1)$ & $2.1(1.2)$ \\
\hline Patients global assessment & $6.5(2.4)$ & $6.5(2.2)$ \\
\hline of asthma symptoms $(0-10)^{\dagger}$ & $\begin{array}{c}7.3^{+} \\
(3.1-8.4)\end{array}$ & $\begin{array}{c}7.2^{+} \\
(2.7-8.7)\end{array}$ \\
\hline $\begin{array}{l}\text { Daily asthma severity } \\
\text { score }(0-12)^{\dagger}\end{array}$ & $\begin{array}{c}5.4(2.4) \\
5.3^{+} \\
(2.7-9.2)\end{array}$ & $\begin{array}{c}5.3(2.6) \\
5.4^{+} \\
(2.1-9.5)\end{array}$ \\
\hline
\end{tabular}

*: data are presented as mean, and range in parenthesis; $\dagger$ : data are presented as mean, and SD in parenthesis; +: median, and range in parenthesis. $\mathrm{F}$ : female; $\mathrm{M}$ : male; IgE: immunoglobulin E; PEF: peak expiratory flow; FVC: forced vital capacity; FEV1: forced expiratory volume in one second; MEF50: maximal mid-expiratory flow.

on this type of asthma for years. All 34 patients were treated with high-dose inhaled corticosteroid, 1,600 $\mu \mathrm{g} \cdot \mathrm{day}^{-1}$, oral theophylline, and $\beta_{2}$-agonist from metereddose inhaler. Sixteen patients received sodium cromoglycate. Mean lung function test results of 34 patients included were: forced vital capacity (FVC): 2.88 (SD 0.99) L (77\% of predicted), FEV1: 2.09 (0.74) L (64\% pred), FEV1/FVC $72 \%$.

\section{Study design}

The study consisted of a 12 week baseline period, followed by 34 weeks of the experimental period and 8 weeks follow-up observation (fig. 1). During the baseline period, all patients received standard asthma treatment (see below). Individual maintenance corticosteroid doses were kept as stable as possible.

Following the baseline period, patients were randomly assigned to parallel treatment groups and took either cyclosporin or placebo for 12 weeks (Part I of the experimental period). During Part II of the experimental period, the treatment with cyclosporin or placebo was continued for 22 weeks. The corticosteroid dose was gradually reduced, according to a standardized protocol, by $10-15 \%$ every 4 weeks; maximum possible reduction that could have been achieved being $75 \%$. 


\section{Experimental period}

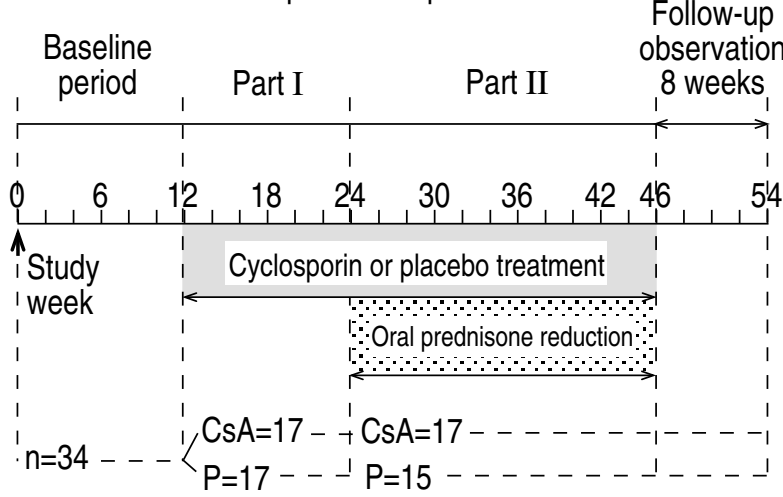

Fig. 1. - Study design. CsA: cyclosporin A; P: placebo.

If during tapering of steroid doses clinical deterioration of asthma or symptoms of upper respiratory tract infection occurred (exacerbation of asthma), patients were treated with standardized 2 week courses of higher doses of oral steroids (usually a doubling of the individual maintenance dose). Part I of the experimental period was designed to detect the effects of cyclosporin on severity of asthma and lung function tests, whilst the aim of the Part II was to examine a possible corticosteroid-sparing effect of cyclosporin.

Upon completion of the 46 week trial, both cyclosporin and placebo were tapered-off over a 2 week period. Patients were followed-up for 8 weeks. During follow-up observation, only the prednisone dose requirement was monitored.

With 17 patients in each group, the study had an $80 \%$ chance of detecting a difference of $6.6 \mathrm{mg}$ or greater in mean daily requirement for corticosteroids at the end of the experimental phase, using $\alpha=5 \%$. This would represent a reduction of $40 \%$ from average doses of corticosteroids recorded at the end of the baseline period.

\section{Clinical protocol}

All patients fitted the entry criteria according to the history, physical examination, and the following investigations: blood count with differential, blood eosinophil number; urinalysis; serum biochemistry (creatinine, urea, electrolytes, bilirubin, serum glutamic oxalo-acetic transaminase (SGOT), alkaline phosphatase (AIP), gammaglutamyltranspeptidase (GGTP), calcium, magnesium, glucose, cholesterol, triglycerides); serum protein electrophoresis and immunoglobulins (IgG, $\operatorname{IgA}, \operatorname{IgM}, \operatorname{IgE})$; chest and maxillary sinus radiography; spirometry (FVC, FEV1, FEV1/FVC\%, maximal mid-expiratory flow (MEF50), measured before and after two puffs of $\beta$-agonist (salbutamol, $100 \mu \mathrm{g} \cdot$ puff $\left.^{-1}\right)$. Skin-prick tests were performed with 16 common aeroallergens (SmithKline and Beecham, UK). Positive skin-prick tests were defined as a wheal $3 \mathrm{~mm}$ greater than negative control. A standard gynaecological examination with colposcopy was performed on all female patients.

Treatment of asthma was standardized throughout the trial and consisted of inhaled steroid (beclomethasone dipropionate, Polfa, Poland) at 1,600 $\mu \mathrm{g} \cdot \mathrm{day}^{-1}$, aminophylline (aminophylline, Polfa, Poland) at 700-1,400 $\mathrm{mg} \cdot$ day $^{-1}$ (dose adjusted to obtain serum theophylline levels between 10-20 $\mu \mathrm{g} \cdot \mathrm{mL}^{-1}$ ) + fenoterol (Berotec, Polfa, Poland) or salbutamol (salbutamol, Polfa, Poland) was administered regularly, at least 6-8 puffs daily, plus additional puffs if required.

Exacerbation of asthma was defined as worsening of asthma symptoms (wheezing, breathlessness, chest tightness, cough) in association with decreased PEF and lack of sustained response to $\beta$-mimetics, as judged both by patient and blinded trial physician. Patients were then treated with a standardized course of higher doses of oral steroids (see above). Additional treatment of asthma exacerbations was prescribed according to routine clinical practice (antibiotics etc.).

During the trial, PEF values, symptom scores and total daily bronchodilator use were recorded every day on asthma diary cards. Morning and evening PEF were measured by mini-Wright peak flow meter (Vitalograph, Buckingham, UK) before and 15-30 min after $\beta_{2}$ agonist administration (three attempts, best value recorded); inhaled bronchodilator use was recorded as number of doses administered during the day and at night. Subjective asthma symptoms were scored 0-4 separately for night-time, at awakening, and for daytime $(0=$ no symptoms, $4=$ very severe $)$.

Daily asthma severity scores were calculated according to the scheme presented in table 2 (modification of the method used by WoOLCOCK and JENKINS [26]), based on: 1) the sum of scores recorded during night-time, daytime and at awakening; 2) daily bronchodilator use; 3 ) daily percentage variability of $\mathrm{PEF}=($ highest $\mathrm{PEF}$ - lowest $\mathrm{PEF} /$ highest $\mathrm{PEF}) \times 100$.

Asthma symptoms, lung function and adverse effects were assessed every 2 weeks by at least two blinded trial physicians. Physical examination was performed at each visit, asthma diary cards were carefully examined and spirometry recorded (FVC, FEV1, MEF50) using computerized pneumotachograph (Pneumoscreen, E. Jaeger, Germany). Subjective global assessment of asthma

Table 2. - Daily asthma severity score (maximum possible range between 0-12)

\begin{tabular}{cccccc}
\hline $\begin{array}{c}24 \text { h symptoms } \\
\text { scores* }\end{array}$ & \multicolumn{2}{c}{$\begin{array}{c}24 \text { bronchodilator } \\
\text { use }\end{array}$} & \multicolumn{2}{c}{$\begin{array}{c}\text { Daily variability } \\
\text { of PEF }\end{array}$} & $\%^{\ddagger}$ \\
\hline 12 & $(4)$ & $>12$ & $(4)$ & $>50$ & $(4)$ \\
$5-11$ & $(3)$ & $9-12$ & $(3)$ & $31-50$ & $(3)$ \\
$2-4$ & $(2)$ & $5-8$ & $(2)$ & $21-30$ & $(2)$ \\
1 & $(1)$ & $1-4$ & $(1)$ & $11-20$ & $(1)$ \\
0 & $(0)$ & 0 & $(0)$ & $1-10$ & $(0)$ \\
\hline
\end{tabular}

*: scores recorded during night-time, daytime and at awakening were added; ${ }^{t}$ : number of doses of bronchodilator administered during the day and at night; $\ddagger$ : (maximum recorded PEF - minimum PEF/maximum PEF) $\times 100 \%$. PEF: peak expiratory flow. Numbers in brackets represent scale $(0-4)$ of intensity of symptoms, $\beta$-mimetic intake, and extent of daily variability of PEF. (Modified from WoolCOCK and JENKINS 
symptoms was also measured every 2 weeks with a visual vertical analogue scale, which consisted of a $10 \mathrm{~cm}$ vertical line labelled "no asthma" at the bottom and "very severe asthma" at the top.

At 4 week intervals, blood count, serum biochemistry (apart from serum creatinine measured every 1-2 weeks), immunoglobulins, and urinalysis (as during screening procedure) were repeated.

Blood trough cyclosporin levels were measured every 1-2 weeks using specific monoclonal antibody radioimmunoassay (Sandimmun-Kit, Sandoz Ltd, Switzerland). Cyclosporin, $25 \mathrm{mg} \cdot$ capsule $^{-1}$, and placebo (Sandoz, Basel, Switzerland) were identical in appearance. Patients were started on $2.5 \mathrm{mg} \cdot \mathrm{kg}^{-1}$ daily of the test medication in two divided doses every $12 \mathrm{~h}$. The dose was increased by $25 \%$ weekly, until a blood trough level of cyclosporin of 75-150 $\mathrm{ng} \cdot \mathrm{mL}^{-1}$ was achieved, unless prevented by a $30 \%$ or more rise in serum creatinine. The dose was reduced if: serum creatinine increased more than $30 \%$ of baseline or above $130 \mu \mathrm{mol} \cdot \mathrm{L}^{-1}$; SGOT or AlP increased twofold above the upper limit of normal; serum potassium increased over $5.0 \mathrm{mmol} \cdot \mathrm{L}^{-1}$; or blood pressure rose and stayed over $160 \mathrm{mmHg}$ systolic or $95 \mathrm{mmHg}$ diastolic. Monitoring of cyclosporin levels, nephrotoxicity and dosage adjustment were performed by an "unblinded clinician", who was neither involved in direct patientstudy contact nor in assessment of the results. To maintain blinding, blood cyclosporin levels were determined in both groups.

\section{Adverse reactions}

All adverse reactions observed by the investigators or reported by the patient were monitored at every followup visit. The patient was asked to identify any new problems or changes that had occurred since the previous visit.

\section{Statistical analysis}

The differences in the variables measured between the treatment groups (cyclosporin vs placebo) were estimated by analysis of covariance (SAS, GLM) using the model adjusting to time and mean baseline measurements of the variable. For the daily dose of prednisone administered during Part II of the experimental period, the analysis of covariance was made on the means of the doses at each time-point.

Wilcoxon test was used to compare the mean of the parameters measured between the baseline period and Part I of the experimental period.

\section{Results}

Thirty four patients entered the study. Following randomization, 17 were assigned to the cyclosporin group and 17 to the placebo group. Thirty two completed the full protocol; two dropped out after completing Part I of the experimental period. These two patients, both from the placebo group, moved out to a distant city and could not accept further frequent follow-up visits.

\section{Baseline period}

The demographic and clinical characteristics of the cyclosporin and placebo group are shown in table 1 . The groups were similar with respect to: mean age, sex distribution, mean duration of asthma, and duration of corticosteroid treatment, atopic status, and the prevalence of aspirin sensitivity.

There were no meaningful differences in diary card analysis, patients' global assessment of asthma symptoms, daily asthma severity score, and lung function tests recorded during the 12 week baseline period (table $1)$.

The mean (SD) corticosteroid dose during the baseline period was similar in cyclosporin and placebo groups; 15.9 (6.9) $\mathrm{mg}$ and 16.5 (7.5) $\mathrm{mg}$, respectively.

\section{Experimental period}

Part I - cyclosporin or placebo treatment. Table 3 gives the adjusted differences and $95 \%$ confidence intervals for mean daily steroid dose, morning and evening PEF (both before and after $\beta$-mimetic, fenoterol), daily PEF variability, FVC, FEV1, FEV1/FVC\%, MEF50, daily asthma severity score and daily $\beta$-mimetic intake. A negative difference presented in table 3 indicates that the means for placebo were higher than for the cyclosporin group.

Following cyclosporin or placebo administration, there were no differences in mean morning and evening PEF values before and after inhalation of $\beta$-mimetic except for higher values of mean morning PEF after $\beta$-mimetic usage in the placebo group.

No significant difference was found in daily PEF variability between the groups studied.

However, the mean $\beta$-mimetic intake both during the day and night was significantly lower in the cyclosporin group than in placebo group during that period. The mean score of subjective asthma symptoms for awakening, daytime, and for night-time were statistically lower in the cyclosporin group. There was no significant difference in the mean and/or median daily asthma severity score and subjective global assessment of asthma symptoms measured every 2 weeks with a visual vertical analogue scale.

There were no significant differences between the groups studied in FEV1, FVC, FEV1/FVC\% and MEF50.

The mean individual doses of corticosteroid were similar to those in the baseline period and did not differ between the treatment groups; 16.3 (SD 7.6) $\mathrm{mg}$ in the cyclosporin group and 16.9 (7.4) $\mathrm{mg}$ in the placebo group.

Part II - cyclosporin or placebo treatment and reduction of oral prednisone dose. After the drop-out of two patients, 32 patients entered and completed Part II of the experimental period; 17 in the cyclosporin group and 
Table 3. - Adjusted difference in subjective asthma assessment scores and volumatic function between cyclosporin (CS) and placebo (P) group in Part I and Part II of experimental phase

\begin{tabular}{|c|c|c|c|c|}
\hline \multirow[t]{2}{*}{$\begin{array}{l}\text { Outcome } \\
\text { measured }\end{array}$} & \multicolumn{2}{|c|}{$\begin{array}{c}\text { Part I } \\
\text { CS or } P \text { treatment }\end{array}$} & \multicolumn{2}{|c|}{$\begin{array}{l}\text { Part II } \\
\text { Oral prednisone reduction during } \\
\text { continued CS or } P \text { treatment }\end{array}$} \\
\hline & Difference* & $95 \% \mathrm{CI}$ & Difference* & $95 \% \mathrm{CI}$ \\
\hline Morning PEF before fenoterol $\mathrm{L} \cdot \mathrm{min}^{-1}$ & -0.3 & -4.0 to 3.5 & -12.6 & -15.4 to -9.8 \\
\hline Morning PEF after fenoterol $\mathrm{L} \cdot \mathrm{min}^{-1}$ & -4.2 & -7.8 to -0.6 & -22.0 & -24.6 to -19.0 \\
\hline Evening PEF before fenoterol $\mathrm{L} \cdot \mathrm{min}^{-1}$ & -2.7 & -6.8 to 1.4 & -7.4 & -10.5 to -4.4 \\
\hline Evening PEF after fenoterol $\quad \mathrm{L} \cdot \mathrm{min}^{-1}$ & -3.9 & -7.9 to 0.1 & -16.5 & -19.5 to -13.6 \\
\hline Daily variability of PEF $\mathrm{L} \cdot \mathrm{min}^{-1}$ & -0.1 & -2.6 to 2.4 & 5.0 & 2.8 to 7.0 \\
\hline Puffs of fenoterol per day $n$ & -0.7 & -1.2 to -0.1 & -0.4 & -0.6 to -0.3 \\
\hline Puffs of fenoterol per night $n$ & -0.6 & -0.8 to -0.5 & -0.4 & -0.7 to 0.0 \\
\hline Symptoms at awakening & -0.3 & -0.3 to -0.2 & -0.2 & -0.2 to -0.1 \\
\hline Daytime symptoms & -0.5 & -1.0 to -0.1 & 0.4 & -0.3 to 1.1 \\
\hline Night-time symptoms & -0.2 & -0.3 to -0.1 & -0.3 & -0.4 to -0.2 \\
\hline Calculated daily asthma severity score (ASS) & -0.1 & -0.3 to 0.1 & 0.2 & 0.0 to 0.3 \\
\hline Subjective global assessment of asthma symptoms & -0.2 & -0.7 to 0.3 & -0.5 & -0.8 to -0.1 \\
\hline FVC $\mathrm{mL}$ & 84 & -80 to 249 & -15 & -141 to 111 \\
\hline FEV $1 \mathrm{~mL}$ & 42 & -96 to 179 & -27 & -131 to 76 \\
\hline $\mathrm{FEV} 1 / \mathrm{FVC} \%$ & -0.6 & -2.6 to 1.4 & -0.8 & -2.4 to 0.8 \\
\hline MEF50 L $\cdot \mathrm{s}^{-1}$ & 0.0 & -0.2 to 0.2 & -0.1 & -0.3 to $<0.0$ \\
\hline
\end{tabular}

95\% CI: 95\% confidence interval. *: negative difference indicates higher mean value in placebo group. For further abbreviations see legend to table 1 .

15 in the placebo group. During the prednisone dose reduction, asthma exacerbations necessitating augmentation in the prednisone dose occurred in $47 \%$ (95\% CI 23-72) of the patients in the cyclosporin group and in $60 \%$ (95\% CI 32-84) of the patients in the placebo group. The mean (SD) duration of asthma exacerbations was 28 (10.9) days in the cyclosporin group and 41 days (17.9) in the placebo group. When the asthma exacerbation subsided, the prednisone dose reduction programme was continued. In total, the final prednisone dose was reduced more than $20 \%$ compared to baseline value in $82 \%$ (95\% CI 57-96) of the patients in the cyclosporin group and in $60 \%$ (95\% CI 32-84) of the patients in the placebo group. These differences were not statistically significant.

There were considerable fluctuations in the mean prednisone dose (the doses added during exacerbations

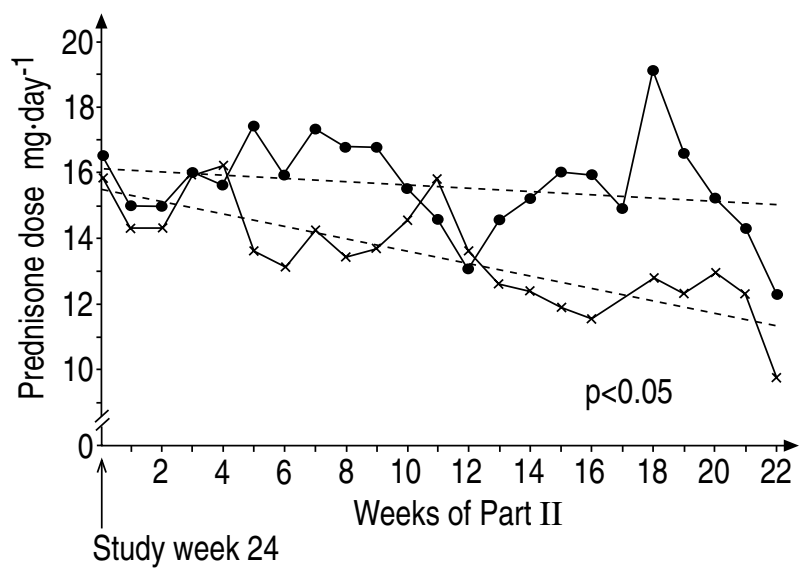

Fig. 2. - Trends in mean daily doses of oral prednisone during Part II of the experimental period in the cyclosporin (CS) and placebo (P) groups. Note that the vertical axis is cut off from zero. - - : placebo; - $\times$ - : cyclosporin. - - -: trend lines for P (upper) and CS (lower). of asthma are included) in both treatment groups as a consequence of asthma exacerbations (fig. 2). Mean prednisone doses were significantly reduced in both treatment groups (from 15.9 to $9.8 \mathrm{mg} \cdot \mathrm{day}^{-1}$ in the cyclosporin group, $\mathrm{p}<0.001$; and from 16.5 to 12.2 $\mathrm{mg} \cdot \mathrm{day}^{-1}$ in the placebo group, $\mathrm{p}<0.01$ ) (table 4). Analysis of covariance showed significant difference in time

Table 4. - Daily prednisone dose at the beginning and the end of Part II of experimental phase in individual subjects in cyclosporin and placebo group

\begin{tabular}{|c|c|c|c|c|c|}
\hline \multirow[b]{3}{*}{ Pt No. } & \multicolumn{2}{|c|}{ Cyclosporin group } & \multirow[b]{3}{*}{ Pt No. } & \multicolumn{2}{|c|}{ Placebo group } \\
\hline & Prednisone & $\mathrm{mg} \cdot \mathrm{day}^{-1}$ & & Prednisone $r$ & $\lg \cdot$ day $^{-1}$ \\
\hline & Beginning & End & & Beginning & End \\
\hline 1 & 10.0 & 7.0 & 1 & 27.5 & 19.0 \\
\hline 2 & 20.0 & 10.0 & 2 & 20.0 & 20.0 \\
\hline 3 & 15.0 & 12.0 & 3 & 22.5 & 22.5 \\
\hline 4 & 20.0 & 20.0 & 4 & 15.0 & 15.0 \\
\hline 5 & 10.0 & 10.0 & 5 & 20.0 & 20.0 \\
\hline 6 & 12.5 & 12.5 & 6 & 10.0 & 10.0 \\
\hline 7 & 35.0 & 21.0 & 7 & 10.0 & 6.0 \\
\hline 8 & 20.0 & 12.0 & 8 & 25.0 & 25.0 \\
\hline 9 & 15.0 & 5.0 & 9 & 15.0 & 9.0 \\
\hline 10 & 10.0 & 5.0 & 10 & 20.0 & 12.0 \\
\hline 11 & 20.0 & 10.0 & 11 & 10.0 & 4.0 \\
\hline 12 & 15.0 & 7.5 & 12 & 25.0 & 10.0 \\
\hline 13 & 10.0 & 5.0 & 13 & 15.0 & 5.0 \\
\hline 14 & 12.5 & 6.0 & 14 & 7.5 & 4.0 \\
\hline 15 & 25.0 & 15.0 & 15 & 5.0 & 2.0 \\
\hline 16 & 5.0 & 1.5 & & & \\
\hline 17 & 15.0 & 7.0 & & & \\
\hline Mean & 15.9 & 9.8 & Mean & 16.5 & 12.2 \\
\hline SD & 7.1 & 5.3 & SD & 7.0 & 7.5 \\
\hline
\end{tabular}

Pt: patients. 
trends of mean daily prednisone doses between the treatment groups $(\mathrm{p}<0.05)$ (fig. 2). However, the difference in the final corticosteroid dose reduction was not significantly different between the treatment groups $(\mathrm{p}>0.05)$.

Both morning and evening mean PEF values (measured before and after $\beta$-mimetic usage) were statistically smaller in the cyclosporin group. The mean daily PEF variability was statistically higher in the cyclosporin group. However, the mean daily $\beta$-mimetic consumption was statistically lower in the cyclosporin group than in the placebo group. The mean score of subjective asthma symptoms for night-time and at awakening was statistically lower for the cyclosporin group. The daily asthma severity score was higher in the cyclosporin group. Subjective global assessment of asthma symptoms was significantly lower in the cyclosporin group. No significant differences between treatment groups were found in mean FVC, FEV1, FEV1/FVC\%; mean MEF50 was significantly higher in the placebo group.

\section{Follow-up observation}

In $35 \%(95 \%$ CI 14-62) of the patients from the cyclosporin group, the diminished prednisone dose could be maintained for at least 8 weeks following cyclosporin withdrawal. In the remaining patients, the prednisone

Table 5. - Means of some physiological and laboratory parameters in cyclosporin and placebo group values during baseline and Part I of experimental period

\begin{tabular}{|c|c|c|c|c|}
\hline \multirow{2}{*}{$\begin{array}{l}\text { Outcome } \\
\text { measured }\end{array}$} & \multicolumn{2}{|c|}{ Cyclosporin group } & \multicolumn{2}{|c|}{ Placebo group } \\
\hline & $\begin{array}{c}\text { Baseline } \\
\text { period }\end{array}$ & Part I & $\begin{array}{c}\text { Baseline } \\
\text { period }\end{array}$ & Part I \\
\hline $\begin{array}{l}\text { Systolic blood } \\
\text { pressure } \mathrm{mmHg}\end{array}$ & $\begin{array}{l}126 \\
(12.1)\end{array}$ & $\begin{array}{r}133 * \\
(15.3)\end{array}$ & $\begin{array}{l}126 \\
(12.1)\end{array}$ & $\begin{array}{l}128 \\
(13.5)\end{array}$ \\
\hline $\begin{array}{l}\text { Diastolic blood } \\
\text { pressure } \mathrm{mmHg}\end{array}$ & $\begin{array}{l}81 \\
(8.3)\end{array}$ & $\begin{array}{r}85^{*} \\
(10.0)\end{array}$ & $\begin{array}{l}79 \\
(9.4)\end{array}$ & $\begin{array}{l}81 \\
(8.2)\end{array}$ \\
\hline HR beats $\cdot \min ^{-1}$ & $\begin{array}{l}78.4 \\
(3.9)\end{array}$ & $\begin{array}{l}79.8^{\dagger} \\
(4.0)\end{array}$ & $\begin{array}{l}79.2 \\
(7.8)\end{array}$ & $\begin{array}{l}78.1 \\
(3.9)\end{array}$ \\
\hline Total WCC $\times 10^{3} \cdot \mathrm{mm}^{-3}$ & $\begin{array}{lc}3 & 8.7 \\
& (2.8)\end{array}$ & $\begin{array}{l}8.1 \\
(2.5)\end{array}$ & $\begin{array}{c}8.6 \\
(3.5)\end{array}$ & $\begin{array}{l}11.1^{\dagger} \\
(2.1)\end{array}$ \\
\hline $\begin{array}{l}\text { Absolute eosinophil } \\
\text { count }\end{array}$ & $\begin{array}{l}190.7 \\
(261.8)\end{array}$ & $\begin{array}{c}193.4 \\
(188.7)\end{array}$ & $\begin{array}{c}212.6 \\
(112.8)\end{array}$ & $\begin{array}{c}201.7 \\
(121.5)\end{array}$ \\
\hline Creatinine $\mu \mathrm{mol} \cdot \mathrm{L}^{-1}$ & $\begin{array}{l}90.5 \\
(11.1)\end{array}$ & $\begin{array}{r}99.4^{\dagger} \\
(16.3)\end{array}$ & $\begin{array}{l}93.2 \\
(8.4)\end{array}$ & $\begin{array}{l}90.8 \\
(8.8)\end{array}$ \\
\hline Cholesterol $\mathrm{mmol} \cdot \mathrm{L}^{-1}$ & $\begin{array}{c}5.4 \\
(0.7)\end{array}$ & $\begin{array}{r}5.9 \\
(0.8)\end{array}$ & $\begin{array}{l}5.5 \\
(0.7)\end{array}$ & $\begin{array}{l}5.8 \\
(0.8)\end{array}$ \\
\hline Potassium $\mathrm{mmol} \cdot \mathrm{L}^{-1}$ & $\begin{array}{l}4.15 \\
(0.3)\end{array}$ & $\begin{array}{r}4.25 \\
(0.2)\end{array}$ & $\begin{array}{l}4.15 \\
(0.3)\end{array}$ & $\begin{array}{l}4.25 \\
(0.2)\end{array}$ \\
\hline Magnesium $\mathrm{mmol} \cdot \mathrm{L}^{-1}$ & $\begin{array}{c}0.95 \\
(0.13)\end{array}$ & $\begin{array}{r}0.83^{*} \\
(0.07)\end{array}$ & $\begin{array}{c}0.93 \\
(0.06)\end{array}$ & $\begin{array}{c}0.91 \\
(0.07)\end{array}$ \\
\hline $\operatorname{IgG} g \cdot L^{-1}$ & $\begin{array}{l}11.5 \\
(3.3)\end{array}$ & $\begin{array}{l}11.4 \\
(3.3)\end{array}$ & $\begin{array}{l}12.1 \\
(3.1)\end{array}$ & $\begin{array}{l}11.5 \\
(2.6)\end{array}$ \\
\hline $\operatorname{Ig} \mathrm{A} g \cdot \mathrm{L}^{-1}$ & $\begin{array}{c}2.7 \\
(1.1)\end{array}$ & $\begin{array}{c}2.7 \\
(1.0)\end{array}$ & $\begin{array}{l}2.9 \\
(0.9)\end{array}$ & $\begin{array}{l}2.8 \\
(0.9)\end{array}$ \\
\hline $\operatorname{IgM} \quad g \cdot L^{-1}$ & $\begin{array}{c}2.2 \\
(1.5)\end{array}$ & $\begin{array}{c}2.2 \\
(1.5)\end{array}$ & $\begin{array}{l}1.9 \\
(0.8)\end{array}$ & $\begin{array}{l}1.9 \\
(0.9)\end{array}$ \\
\hline
\end{tabular}

Data are presented as mean and SD in parenthesis. HR: heart rate; WCC: white cell count; Ig: immunoglobulin. *: p<0.001; $\ddagger$ : $<<0.01 ; \dagger: \mathrm{p}<0.05$ (baseline versus Part I). dose had to be increased because of asthma exacerbations. In the placebo group, diminished prednisone doses were maintained for 8 weeks in only $20 \%$ of patients (95\% CI 4-45). This difference between the groups studied was not statistically significant.

Table 5 shows laboratory parameters during baseline and Part I of the study. Mean heart rate, systolic and diastolic blood pressure, serum creatinine and cholesterol levels increased significantly in the cyclosporin group, whereas magnesium level fell significantly in this group. These changes did not occur in the placebo group. Serum immunoglobulin levels were not affected by the treatment.

\section{Side-effects}

During cyclosporin treatment, mild gastrointestinal symptoms were temporarily reported (nausea and diarrhoea in $29 \%$ (95\% CI 10-56) and $12 \%$ (95\% CI 2-36) of patients, respectively). Patients on placebo did not report such symptoms.

Mild paraesthesiae were reported by $28 \%$ (95\% CI 10-56) of patients taking cyclosporin. These symptoms were transient and of slight intensity and did not prompt us to withdraw the drug.

Mild hypertrichosis, reported by the subjects studied, was noted in $24 \%$ (95\% CI 7-50) of patients in the cyclosporin group compared to $12 \%$ (95\% CI 2-40) of patients in the placebo group. All symptoms improved with time and resolved completely within 4 weeks of drug withdrawal.

\section{Discussion}

In this study, we have presented evidence that following cyclosporin administration a slight beneficial effect in some subjective parameters of asthma severity was observed, whilst we did not observe any beneficial effect of cyclosporin treatment on pulmonary function. Cyclosporin seemed to be slightly more efficient than placebo in reducing the requirement for systemic corticosteroid, even though the steroid reduction was accompanied by slight impairment of some pulmonary function.

Although the precise mechanism of action of cyclosporin in asthma is unknown, its effects are probably related to immunoregulatory and antiinflammatory activity $[27,28]$. In asthma, the cyclosporin target cell may be the T-lymphocyte, mast cell or basophil, or a combination of these and other cell types.

The drug exerts its major effect by inhibition of T-cell activation [13]. This, in turn, prevents the transcription of the genes that encode the cytokines, co-ordinating various cells involved in the immune response. The exact molecular mechanism of action of cyclosporin remains elusive $[12,13,29]$. Cyclosporin functions as a prodrug and becomes active when complexed to an intracellular receptor, a binding protein known as cyclophilin [13]. Cyclosporin-cyclophilin complex blocks translocation of the cytoplasmatic component of the nuclear factor of 
activated T-cells (NF-AT) to the nucleus by inhibition of calcineurin; the subsequent activation of genes that encode cytokines becomes inhibited [13, 29].

Cyclosporin also inhibits: 1) mediator release from mast cells and basophils $[14,15]$; 2) antigen presentation by antigen-presenting cells [16]; 3) interleukin4 (IL-4)-induced immunoglobulin E (IgE) synthesis, both in B-cells from atopic individuals and in in vitro preactivated normal B-cells [30]; and 4) expression of cutaneous IgE-dependent and platelet-activating factor (PAF)-induced late-phase reactions [31].

Thus, cyclosporin may modulate the immune response in asthma and reduce the inflammatory process in the airway wall; thereby, attenuating asthma symptoms and reducing the need for systemic corticosteroid treatment $[27,28]$.

Both during the baseline period and Part I of the experimental period (when cyclosporin or placebo were added to standardized treatment of asthma), we analysed several parameters that reflect the severity of asthma symptoms. In our study, during the baseline period, there were no meaningful differences between cyclosporin and placebo groups in most analysed parameters.

Following cyclosporin administration, mean subjective asthma symptom scores (analysed at awakening, during the day, and at night) were significantly lower than in patients following placebo administration. Similarly, both the mean and median daily asthma severity score, and mean and median subjective global assessment of asthma symptoms analysed every 2 weeks with visual analogue scale, were lower in the cyclosporin group but without reaching the level of statistical significance.

These results could have suggested greater beneficial effect of cyclosporin on asthma symptoms and severity. The suggestion was also supported by the finding that cyclosporin treatment was associated with less use of $\beta$ mimetic inhalations. However, we did not observe any beneficial effect of cyclosporin on such objective parameters of pulmonary function as FVC, FEV1, FEV1/ $\mathrm{FVC} \%$ and MEF50.

Following cyclosporin or placebo treatment, there were no differences in mean morning and evening PEF values before and after $\beta$-mimetic usage, except for higher values of mean morning PEF after $\beta$-mimetic inhalation in placebo group. The theoretical explanation for this phenomenon could be the diminished response to $\beta$-mimetics during cyclosporin treatment.

Our findings do not confirm the evident beneficial effect of cyclosporin treatment recently reported by AleXANDER et al. [24]. They found that cyclosporin treatment resulted in a mean increase of $12 \%$ in morning PEF and $18 \%$ in FEV1 over placebo, whilst diurnal variation in PEF decreased by a mean of $28 \%$. Moreover, despite significant improvements seen in pulmonary function, these authors did not observe a diminution in bronchodilator consumption nor changes in the mean symptom score, as found in our study. Their study differed from ours in the following ways: 1) ALEXANDER et al. [24] conducted a double-blind, cross-over study to detect intrasubject improvement in lung function, whilst we used a double-blind, placebo-controlled parallel group design; 2) 32 patients, who entered the study of ALEXANDER et al. [24], had significantly lower requirements for oral corticosteroids than our patients (mean dose 8.5 vs 16.5 $\mathrm{mg}$ ); 3) bronchodilator consumption was almost half that of our patients; 4) and finally ALEXANDER et al. [24] used higher doses of cyclosporin: $5.22 \mathrm{mg} \cdot \mathrm{kg}^{-1}$ body weight (blood cyclosporin trough levels varied from 46-217 $\mu \mathrm{g} \cdot \mathrm{L}^{-1}$, mean value $152 \mu \mathrm{g} \cdot \mathrm{L}^{-1}$ ), whilst we administered $3-5 \mathrm{mg} \cdot \mathrm{kg}^{-1}$ and obtained cyclosporin levels of $70-150 \mu \mathrm{g} \cdot \mathrm{L}^{-1}$, mean value $120 \mu \mathrm{g} \cdot \mathrm{L}^{-1}$. These differences could, in part, explain why the results of ALEXANDER et al. [24] varied from ours. Moreover, these authors recorded 13 asthma exacerbations in patients receiving placebo compared to four in patients on cyclosporin treatment, which suggests that their patients were more unstable, since introduction of the test medication, without steroid reduction, precipitated so many exacerbations of asthma.

There are few reports on the effects of cyclosporin on experimental models of asthma. ARIMA et al. [32] found, in guinea-pigs, that cyclosporin did not inhibit the immediate allergen-induced bronchoconstriction, but did inhibit development of the late asthmatic response and associated bronchial hyperresponsiveness. On the other hand, ELwood et al. [33] observed, in rats, that cyclosporin did not prevent bronchial hyperresponsiveness induced by ovalbumin, whilst it produced significant inhibition of eosinophil and lymphocyte influx [33].

The results of the second part of our study, devoted to the possibility of steroid reduction, might suggest that cyclosporin administration can facilitate the reduction of corticosteroid dose. However, the differences between the groups studied in proportions of patients in whom corticosteroid dose reduction was achieved, in mean duration of asthma exacerbations and in proportions of patients with asthma exacerbations were not significant. Both absolute and percentage steroid reduction during cyclosporin treatment were not very high, but in patients on chronic corticosteroid treatment for many years, even $20-40 \%$ reductions in maintenance doses could probably induce fewer side-effects and, thus, be beneficial.

The analysis of daily PEF values during the steroid reduction phase indicates that patients receiving cyclosporin had significantly lower values both of morning and evening PEF in comparison with patients on placebo, with corresponding significantly higher values of daily asthma severity score. This could have indicated that in those patients the greater steroid reduction could have been achieved at the expense of worsening of pulmonary function tests. On the other hand, $\beta$-mimetics consumption, reflecting in some way patient's subjective assessment of asthma severity, was significantly smaller in patients taking cyclosporin. Comparatively subjective asthma symptom scores for night-time and at awakening were significantly lower in the cyclosporin group, with the same tendency in subjective global assessment of asthma symptoms. All of these results indicate a better self-assessment by patients treated with cyclosporin, despite lower daily PEF measurements and unchanged spirometric parameters.

In the first open trial on the effect of cyclosporin on 
steroid-dependent asthma [21], we found that steroids could be reduced in almost half of our patients without deterioration of pulmonary function tests. Thus, in the present double-blind study, we did not obtain as good results as in our first open study, or as those in a study by FinNERTY and Sullivan [23]. We did not detect any clinical differences (age, sex, atopy, aspirin intolerance) between the group of patients in whom steroids could be reduced and those in whom these efforts were unsuccessful.

The response to cyclosporin withdrawal varied substantially among patients. In $35 \%$ of the cyclosporin group and in $20 \%$ of the placebo group the diminished corticosteroid dose could be maintained for at least 8 weeks following cyclosporin withdrawal. These differences were not statistically significant, indicating no evident long-lasting improvement in prednisone requirement following cyclosporin withdrawal. Exacerbation of asthma following cyclosporin withdrawal was also noted previously by our group [22], and by FINNERTY and Sullivan [23]. These results resemble those in other autoimmune diseases [17-19].

Following introduction of cyclosporin (Part I of the experimental period) we noticed significant increases both in systolic and diastolic blood pressure. In our clinical study, the blood eosinophil count did not change after administration of either cyclosporin or placebo. Cyclosporin is known to inhibit antigen-induced eosinophilia in experimental models [34]. Many authors have shown that in humans cyclosporin treatment increases serum creatinine [35] and cholesterol levels, and diminishes the serum magnesium concentration. The same trends were observed in our study following introduction of cyclosporin. We did not monitor the glomerular filtration rate (GFR) during cyclosporin treatment, as recent studies have shown that serum creatinine is probably better than measurements of GFR in predicting cyclosporin nephropathy, because it can be measured frequently [36].

We did not observe any severe side-effects of cyclosporin treatment. Some patients experienced slight hypertrichosis, but this symptom was subjectively assessed only by patients themselves on the demand of research staff, and could be overestimated by them. A high proportion experienced nausea and diarrhoea during the first 4-8 weeks of cyclosporin treatment. These side-effects were of rather mild severity and disappeared spontaneously, or following some diminution of the cyclosporin dose. Although paraesthesia was frequently noted, it was of low intensity. None of these side-effects forced us to withdraw the test medication. All these symptoms disappeared completely within weeks of cessation of cyclosporin treatment.

In this double-blind, placebo-controlled, parallel group trial we found that cyclosporin had a slight beneficial effect on some subjective parameters of asthma severity and no detectable beneficial influence on pulmonary function. Cyclosporin treatment, however, seemed to be somewhat more efficient than placebo in reducing the requirement for prolonged prednisone treatment in asthmatic patients in whom previous attempts to reduce the prednisone dose were unsuccessful.
These data and the known toxicity of cyclosporin suggest that cyclosporin treatment should have a limited place in the treatment of severe cases of steroid-dependent asthma.

Acknowledgements: The authors acknowledge the excellent technical assistance of J. Suska, A. Kruczek, I. Lipiarz, A. Wolska and I. Duraj.

\section{References}

1. Barnes PJ. Asthma: new therapeutic approaches. $\mathrm{Br}$ Med Bull 1992; 48: 231-247.

2. Corrigan CJ, Brown PH, Barnes NC, Tsai JJ, Kay AB. Glucocorticoid resistance in chronic severe asthma: peripheral blood T-lymphocyte activation and a comparison of the T-lymphocyte inhibitory effects of glucocorticoids and cyclosporin A. Am Rev Respir Dis 1991; 144: 10261032.

3. Nierop G, Gijzel WP, Bel EH, Zwinderman AH, Dijkman $\mathrm{JH}$. Auranofin in the treatment of steroid-dependent asthma: a double-blind study. Thorax 1992; 47: 349-354.

4. Mullarkey MF, Blumenstein BA, Andrade WP, Bailey GA, Olason I, Wetzel CE. Methotrexate in the treatment of corticosteroid-dependent asthma. N Engl J Med 1988; 318: 603-607.

5. Shiner RJ, Nunn AJ, Chung KF, Geddes DM. Randomized, double-blind, placebo-controlled trial of methotrexate in steroid-dependent asthma. Lancet 1990; 336: 137-140.

6. Wald JA, Friedman BF, Farr RS. An improved protocol for the use of troleandomycin in the treatment of steroid-dependent asthma. J Allergy Clin Immunol 1986; 78: 36-43.

7. Boulet L-P, Cartier A, Cockcroft DW, et al. Tolerance to reduction of oral steroid dosage in severly asthmatic patients receiving nedocromil sodium. Respir Med 1990; 84: 317-323.

8. Hodges NG, Brewis RAL, Howell JBL. An evaluation of azathioprine in severe chronic asthma. Thorax 1971; 26: 734-739.

9. Berlow BA, Liebhaber MI, Dyer Z, Spiegel TM. The effect of dapsone in steroid-dependent asthma. J Allergy Clin Immunol 1991; 87: 710-715.

10. Lacronique J, Renon D, Georges D, Henry-Amar M, Marsac J. High-dose beclomethasone: oral steroidsparing effect in severe asthmatic patients. Eur Respir J 1991; 4: 807-812.

11. Corrigan CJ, Kay AB. CD4 T-lymphocyte activation in acute severe asthma: relationship to disease severity and atopic status. Am Rev Respir Dis 1990; 141: 970-977.

12. Erlanger BF. Do we know the site of action of cyclosporin? Immunol Today 1992; 13: 487-490.

13. Schrieber SL, Crabtree GR. The mechanism of action of cyclosporin A and FK506. Immunol Today 1992; 13: 136-142.

14. Triggiani M, Cirillo R, Lichtenstein LM, Marone G. Inhibition of histamine and prostaglandin $\mathrm{D}_{2}$ release from human lung mast cells by cyclosporin A. Int Arch Allergy Appl Immunol 1989; 88: 253-255.

15. Hultsch T, Rodriguez JL, Kaliner MA, Hohman RJ. Cyclosporin A inhibits degranulation of rat basophilic leukemia cells and human basophils: inhibition of mediator release without affecting PI hydrolysis or $\mathrm{Ca}^{2+}$ fluxes. J Immunol 1990; 144: 2659-2664. 
16. Granelli-Piperno A. Lymphokine gene expression in vivo is inhibited by cyclosporin A. J Exp Med 1990; 171: 533-544.

17. Tugwell P, Bombardier C, Gent M, et al. Low-dose cyclosporin versus placebo in patients with rheumatic arthritis. Lancet 1990; 335: 1051-1055.

18. Ellis CN, Fradin MS, Messana JM, et al. Cyclosporin for plaque-type psoriasis: results of a multidose, doubleblind trial. N Engl J Med 1991; 324: 277-284.

19. Sawden JM, Berth-Jones J, Ross JS, et al. Double-blind, controlled, cross-over study of cyclosporin in adults with severe refractory atopic dermatitis. Lancet 1991; 338: 137-140.

20. Szczeklik A, Niżankowska E, Dworski R, Domagaka B, Pinis G. Cyclosporin (CS) for steroid-dependent asthma. Allergy 1991; 46: 312-315.

21. Niżankowska E, Dworski R, Szczeklik A. Cyclosporin for a severe case of aspirin-induced asthma. Eur Respir $J$ 1991; 4: 380 .

22. Szczeklik A, Niżankowska E, Sładek K. Cyclosporin and asthma. Lancet 1992; 339: 873.

23. Finnerty NA, Sullivan TJ. Effect of cyclosporin on corticosteroid-dependent asthma. J Allergy Clin Immunol 1991; 87: 297A.

24. Alexander AG, Barnes NC, Kay AB. Trial of cyclosporin on corticosteroid-dependent asthma. Lancet 1992; 339: 324-328.

25. Szczeklik A, Niżankowska E. Pharmacological agents in bronchial provocation tests. In: Allegra L, Braga PC, Dal Negro R, eds. Methods in Asthmology. Berlin Heidelberg, Springer-Verlag, 1993; pp. 253-264.

26. Woolcock AJ, Jenkins CR. Assessment of bronchial responsiveness as a guide to prognosis and therapy in asthma. Med Clin North Am 1990; 74: 753-765.
27. Calderon E, Lockey RF, Bukantz SC, Coffey RG, Ledford DK. Is there a role for cyclosporin in asthma? J Allergy Clin Immunol 1992; 89: 629-636.

28. Editorial. Cyclosporin in chronic severe asthma. Lancet 1992; 339: 338-339.

29. Liu J, Farmer JD, Lance WS, Friedman J, Weissman I. Calcineurin is a common target of cyclophilin-cyclosporin A and FKBP-FK506 complexes. Cell 1991; 66: 807-815.

30. Peleman R, Wu CY, Delespesse G. Cyclosporin A suppresses the IL-4-induced IgE synthesis. J Allergy Clin Immunol 1990; 85: 232A.

31. Finnerty NA, Sullivan TJ. The effect of low dose of cyclosporin on cutaneous late-period reactions. J Allergy Clin Immunol 1990; 85: 266A.

32. Arima M, Yukawa T, Terashi Y, Makino S. Cyclosporin A inhibits allergen-induced late asthmatic response and increase of airway hyperresponsiveness in guinea-pigs. Nippon Kyobu Shikkan Gakkai Zasshi 1991; 29: 1089_ 1095.

33. Elwood W, Lotvall JO, Barnes PJ, Chung KF. Effect of dexamethasone and cyclosporin A on allergen-induced airway hyperresponsiveness and inflammatory cell responses in sensitized Brown Norway Rats. Am Rev Respir Dis 1992; 145: 1289-1294.

34. Norris AA, Jackson DM, Eady RP. Protective effects of cyclophosphamide, cyclosporin A and FK506 against antigen-induced lung eosinophilia in guinea-pigs. Clin Exp Immunol 1992; 89: 347-350.

35. Feutren G, Mihatsch J. Risk factors for cyclosporininduced nephropathy in patients with autoimmune diseases. N Engl J Med 1992; 326: 1654-1660.

36. Feutren G, Mason J. Serum creatinine or glomerular filtration for monitoring cyclosporin therapy. Lancet 1991; 338: 1017. 